\title{
From Theory to Practice: The Process of Participatory Theatre in Community Development
}

\author{
Evans Asante (Corresponding author) \\ Department of Theatre Arts \\ University of Education, Winneba \\ E-mail: eyasante@uew.edu.gh
}

Received: January 17, 2022 Accepted: February 9, 2022 Published: March 2, 2022

doi: 10.5296/jsss.v9i1.19467

URL: https://doi.org/10.5296/jsss.v9i1.19467

\begin{abstract}
A major concern in community development is the application of various theories, practices, and models that are relevant to the development agenda of the selected community. Participatory theatre practice has been identified as one of such models linking theory and practice in a community development process. Students undergoing training in participatory theatre and community development are introduced to several theories and concepts whose application in the field of work may be quite different from the classroom experience. This paper explores pertinent participatory theatre theories, concepts, and ideals and how they can be effectively put to use at the communal level to achieve an expected outcome. The paper aims to present an easy practical approach to participatory theatre practice in community development.
\end{abstract}

Keywords: community development, community engagement, facilitator, participatory theatre, performance

\section{Introduction}

Community development takes place in many different settings and contexts. As far as the development needs of communities are concerned, practitioners must understand the cultural and social structure of the communities in which they operate. Even though community development may happen in different forms, there are certain theories, concepts, and applications, which remain unchanged. Community development agents and facilitators must therefore take cognizance of these unchanging facts in their application of the theories and concepts. Theories and concepts are mostly the basis for practicality at the communal level, but research reveals that theories are contextualized within the framework of the selected community during practice. Once contextualization takes place, one can gainfully understand 
and employ the theory to achieve an expected outcome within the confines of the community. Typical participatory development practice has three main stages-the beginning, the middle, and the implementation stage. Each stage of the development process has distinctive elements associated with it. The beginning stage is where the facilitators or the development agents begin their search for communities and relevant issues to address. This stage involves active interaction with the community members to come out with relevant, pressing, and popular development challenges confronting them.

The middle stage is where the facilitators engage with the communal folks and other stakeholders into finding possible ways of addressing the issues realized in the first stage. The issues are most often contextualized and so it is mostly advisable to firstly, all look within the confines of the community in search of solutions. Ordrink (1996) opines that local ideas are more popular to the community folks and therefore its application is always easier and results-oriented.

The final stage which is implementation is the realization, actualization, and application of the various development ideas for the benefit of the people. The main objective of this paper is to create a link between the various theoretical stages and their practical application in the field of work. The work aims at practicalizing the theories embedded in each stage of the participatory development practice.

\section{Philosophical Basis for Participation in Community Development}

The participatory development theory paradigm opposes the egalitarian top-down ethnocentric view of development where development processes are mostly left in the hands of few individuals (Pigg, 2010). It rather promotes a more freely cooperation communal bottom-up approach to development where community members are empowered to take charge of their development agenda. In this sense, development begins with the people at the base not the usual top-down imposition kind of development process. Brennam et.al (2014) opined that this liberal bottom-up approach to development encourages the involvement of all stakeholders in the process of the development action.

Participation evokes the community members' interest in the decision-making process towards the realization of the development agenda. Through active and democratic participation, a sense of community ownership is created for the development outcome. Pigg (2010), defined participation as harnessing the existing physical-economic, and social resources of a community to achieve developmental goals. In addition to his definition is amassing and utilizing the human capital of a given community to achieve a realistic development agenda. A key concept of community growth includes collaborating with the community members in their development efforts; taking initiatives, consultations, action plans, and implementation. This action is imperative because the community members understand the dynamics and modalities of their community more than the outsider (development agents). The development agents in this case must serve as the propellers of the development action who creates the awareness and the need for such action as well as the platform for the community members to operate. This can build the capacities of the community members in the long term to sustain the projects and their associated benefits. It 
gives power and strength to community members to take charge of their developmental needs as far as they can.

\section{Participatory Development.}

According to Richards (2001), participation as an approach to development began in the first instance, as an approach intended to subvert development convention. According to him, this approach is not a modern concept as most people think, having first appeared in the development literature in the 1950s. Participatory development became the logical direction to take concerning so many failed, wasted, and damaging top-down approaches to projects and programs. Participation thus became known as being synonymous with democracy, equity, and popular success. Richards sums up the definitions of participatory development as " The empowerment of the people to effectively involve themselves in creating the structures and in designing policies and programs that serve the interests of all as well as to effectively contribute to the development process and share equitably in its benefits". (2001). The expose on participatory development given by Richards makes it clear that Participatory Development is a concept of empowerment of individuals and communities so that they can prioritize, implement and solve their problems, in addition to challenging the wider political causes of such problems.

Participatory development is a people-centered, decentralized, and adaptive approach to the process of development. This practice is characterized as a need; directed and focuses on development at the grassroots or community level. This is in contrast to the sterile, top-down, and centralized development approaches made popular in the past fifty years in the case of Ghana. According to Chambers (1998), new ways have been discovered to enable those who are poor, marginalized, illiterate, and excluded to analyze their realities and express their priorities. The realities they express through conditions, problems, livelihood strategies, and priorities often differ from what is perceived by development practitioners.

Adebo (1996) in his work Participatory Training Manual has outlined six reasons why development agents must adopt the participatory process of development in their community enterprises. Below are the summations of his ideas;

a. Participation, as a concept, is seen as a requirement. Governments and institutions interested in greater productivity at low cost are increasingly in need of 'participation' for their purposes. They have also learned to control the risks in possible unruly abuses of participation.

b. Participation has become a politically attractive slogan: important political advantages are obtained through the overt display of participatory intentions. Participatory slogans create feelings of collusion between the public manufacturers of the participatory illusion and their consumers.

c. Participation has become, economically, an appealing proposition. Because of small government funds, especially those devoted to rural development, participation is in the low-cost option. Some, cynically, see this as passing on government costs to the poor.

d. Participation is perceived as an instrument for greater effectiveness as well as a new source of investment. Participatory Approaches bring a close knowledge of the 'field 
reality' which foreign techniques and government bureaucrats do not have; networks on relations, essential both to the success of on-going projects and long term investments in rural areas; the cooperation, on the local scene, or organizations able to carry out development activities. In this context, grassroots organizations are becoming the infrastructure through which investment is made.

e. Participation is becoming a good fundraising device. In the last ten years, development-oriented NGOs have become very much 'in vogue. This is due to the reputation of NGOs and their participatory and fewer bureaucratized approaches allow them to meet the needs of the people with greater efficiency and at less cost.

f. An expanded concept of participation could help the private sector to be directly involved in the development business: private corporations and consulting agencies associated with development have been (successfully) lobbying for the privatization of development, arguing that governments and international aid agencies waste taxpayer's money.

To raise awareness of community problems and cross the social barriers, which prevented the discussion of such problems, culturally sensitive methods, and approaches have been developed to facilitate the participatory development process in various communities. One of these techniques is what Chambers (2014) refers to as 'the mirror technique'. This is a technique that uses local drama, songs, role-play, films, and poems at large rallies. The technique places a 'mirror' through performance in front of the community so that it can detect and understand its problems. The method emphasizes the identification of social and cultural constraints that limit communal dialogue on issues that affect the entire community.

\section{The Theory of Participatory Theatre}

Development practitioners are increasingly exploring new forms of dialogue in the area of development communication to encourage active participation. Participatory Theatre has been identified as one of the mediums that can create a common platform for community dialogue. Borrowed from the theory of participation, Participatory Theatre is that kind of theatre, which involves the active participation of all community members. It is a community-based media, which employs the people's own indigenous art forms like drumming, songs, myths, and other popular cultural elements to enhance the dramatic presentation process. Participatory Theatre is seen as a community-based learning strategy in which theatre is used as the main platform for the learning process that is aimed at developing the individual and his community. Participatory Theatre productions offer communities the opportunity to actively reflect together by using the stage as a place to explore new ways of living and to express new visions of the future (Mda, 1990). It is described as an art form having 'considerable advantages over music or the visual arts by criteria of accessibility. Its practice is immediate'. The language of drama is seen as the language of social experience, and comparisons are drawn between improvisations as part of the dramatic process and the 'improvisations' that each and everyone one of us undertakes every day of our lives as we experience new and different situations. This form presents the opportunity for an inclusive, democratic, and liberal development process in a community.

\section{Why Participatory Theatre?}


Participatory Theatre as described as an art form has considerable advantages over music or the visual arts by criteria of accessibility. It has an advantage of 'immediacy effect' to its practice. A participatory theatre is an approach in which the actors interact with the community, based on a real problem. Throughout the participatory event, the community participates to adapt, change or correct a situation, an attitude, or a behavior that is impeding the development of the community.

Theatre is seen as non-discriminatory because no physical or mental condition might prevent a level of participation. Participatory Theatre has the 'repeater' possibilities. This keeps the messages alive and gives the project a longer lifespan, which can produce multiplier effects.

Participatory Theatre engages both the head and the heart (Malamah-Thomas, 1986). In the realm of imagined experience, the audience takes on roles of other characters and experience different situations, so that their understanding of themselves, of others, and of the world we live in grows. Participatory theatre productions offer communities the opportunity to actively reflect together by using the stage as a place to explore new ways of living and to express new visions of the future. Suguna (2006) explains that community empowerment is a process and an end in itself. As a process, she explains it as a means by which powerless people conscious of their situation can organize themselves collectively to access a public service to the benefit of their community. So the 'process' here is the ability to consciously come together to achieve a kind of growth for the community. Participatory theatre affords communities that leverage to come together to actively reflect their issues and find indigenous solutions. When people are empowered to take charge of their communities, they gain understanding and total control over their personal, social, economic, and political forces and can take action to improve their life situations.

\section{The Participatory Theatre Practice}

As a practice, knowledge in Participatory Theatre is embodied, culturally located, and socially distributed (Kerr, 1995). This means that knowledge is produced through interaction with others and that reciprocity between participants creates new forms of social and cultural capital.

Participatory theatre methods allow community folks to build and articulate collective knowledge about their experiences and can develop arguments about various issues confronting them.

The participants try out various social interventions, thereby broadening their knowledge in participating in democratic deliberation, both through debate and in everyday practices. It offers a platform for collaborative work between researchers and community members who become the spectators and actors at the same time.

Participatory Theatre employs dance, music, and oral narratives as key elements for community engagements. Key techniques include Forum Theatre, Playback Theatre, and Image Theatre.

Forum Theatre constitutes a series of performance workshops in which the participants are transformed from ordinary audiences into active actors and creators of the various scenarios. They construct scenarios involving oppressive and unpleasant situations in small groups and show them to the other participants who intervene by taking the place of the protagonists and 
suggesting better strategies for achieving their goals.

Playback Theatre creates the platform for community folks to see themselves in their own stories. Stories collected from them are played back to them. This creates a reflective distance between themselves and their stories. The actors constitute a mirror within which the community folks see aspects of themselves. This enables a reordering of the experience as the old version of events has to be assessed in the light of the new.

With Image Theatre, symbolic images of the various confronting issues are created; and participants are given the chance to discuss and suggest ideal solutions to such issues. Discussing images among community folks enable the manifestations of emotions and memories that mere words might conceal.

Collective theatre games, image work, character building, and rehearsals are the main stages that lead to the Forum Theatre final scenes.

\section{Community Development through Participatory Theatre}

The process of effective community development most often begins when:

a. a challenge or opportunity presents itself, and the community responds

b. community members are aware of their power to act together to benefit their community;

c.there is a desire to build on diversity and to find common ground

d. When a process is understood to be a positive approach to manage a certain occurrence in the community.

Participatory Theatre for community development prioritizes empowerment, social inclusion and cohesion, shared responsibility, and social mobility. The medium for interaction in a participatory theatre includes music, songs, dances, and other cultural expressions of the selected community. The facilitator (s) must always consider the cultural context of the selected medium for expressions before applying them within the community dialogue process.

\section{Phases of Participatory Theatre for community development}

Participatory theatre emphasizes three main issues on three main levels (phases) in the community development process; the process (how problems are identified and play made) the product (the play itself) and interaction. The process is the problem identification stage, where facilitators and community members come together to search within the community to identify possible common development issues. This must be always done with the community members because their active involvement promotes a sense of community ownership of the project. The Product is a dramatic skit that is created from the issues identified from the process stage. These issues must reflect the ideals of the community. The play is built on the popular culture of the community. The final stage which is interaction is where the platform is created for the performance and subsequent discussion of the issues projected in the performance. The stage provides the platform for community interaction, creating a democratic avenue for discourse on community issues. A typical community based participatory theatre has the following stages of intervention;

a. community identification 

b. problem identification
c. story creation
d. rehearsals
e. performance
f. post-performance
g. evaluation

All these stages of intervention are embedded in the three main stages discussed above. However, community theatre facilitators must explicitly deal with each stage of intervention to achieve better results from the project.

\section{Practical Steps in Participatory Theatre}

A common Participatory Theatre Performance consists of the following steps for proper implementation:

a. Practitioners live within the community or may visit the community on an ongoing basis for a long duration of time. This allows the facilitator enough time to adjust to the cultural norms, to build trust/relationships, and observe the daily life of the people.

b. Community members create performances based on issues related to the causes of their underdevelopment through the guidance of the facilitators.

c. Key issues are researched and linked by practitioners to the appropriate agencies, which may have a relation to the cause or solution to the issues.

d. Solutions are created through the participatory forum in which the community act out interventions.

e. Action plans are formulated for the community, governmental and international agencies for the appropriate application.

The interactive and participatory dynamic of community theatre fosters a network of human relationships that have unique systems of communication. Participatory Theatre offers an alternative route to developmental goals, in that the tools utilized are centered on dynamics of human relationships and experience. While traditional development practices offer outside assistance through economic aid or loans, Participatory Theatre works within the target community to define the causes of underdevelopment and to find viable solutions that promote self-help. To do this, Participatory Theatre practitioners must understand the atmosphere of the communities that it serves.

\section{The Realistic Approach to Participatory Theatre Practice}

According to the early practitioners, Participatory Theatre practice is a marriage between both process and product. The process is the community-based research and the product being the performance. Asiamah (2016), Prenkti (1998), and Asante\& Yirenkyi (2020) have outlined the practical approach of undertaking a community-based participatory theatre project. According to them, the Participatory

Theatre Practices cover the ground between:

a.initial community research, 
b. workshop explorations of its outcomes

c.performances sharing these outcomes with the community and beyond

d. and any resultant cultural action that might lead to a change in community status, attitudes, behavior, and conditions.

The final target, as in all participatory theatre practice would be an empowered community that

e.have explored and celebrated their identity through performance

f.expressed and analyzed their concerns and difficulties through their performance.

Participatory Theatre gives the opportunity to actively reflect together by using the stage as a place to explore new ways of life within. A group of actors will present a play based on their findings and perceptions after a community inquest; this they will do depending on local circumstances. If their performance becomes a separate entity from their community research findings, it may well reduce their enthusiasm and commitment to the work.

\section{Rehearsing with the community}

Rehearsal is an important phase of the participatory theatre process. It provides the opportunity for the community participants to develop their skills and learn the rudiments of community theatre practice. They also rediscover their potential as community change agents within the confines of the ongoing project. The purpose of the rehearsal is to repeat the performance multiple times for the group to get acclimatized with themselves and the subject matter.

In rehearsing with the community, the following structure and ideas must be followed;

a. Warm-up exercises

b. Recap of previous events

c. The main activity for the day

d. Open forum (discussion of main activity for the day)

e.Evaluation of the day's activities.

All these steps must involve all participants as much as possible. There must always be a target (set goals) for each rehearsal period.

\section{Staging Participatory Theatre}

Theatre in the round (arena theatre) has always been the preferred stage for participatory theatre. With the arena stage, the audience feels included and a kind of communal intimacy is created. It also allows for a wider audience within a given space. Research indicates that the central part of the stage is its strongest area. Facilitators must consciously place key performers in the central part of the stage for easy accessibility and visibility by the audience. During performances, the performers must try as much as possible to avoid "showing their backs to the audience". Eye contact is very important in community theatre practice to engage and attract the audience's attention.

\section{Performers- Audience Relationship}

It is always vital to select some key or prominent people from the community to be part of the 
performing group. These persons serve as the elements of attracting community members to the performance grounds. In a similar manner, and almost invariably, there may be some prominent members of the community forming part of the audience. The presence of the two sects moves the performance beyond mere entertainment but rather, sets the path for community dialogue. It is therefore imperative for the performers to consciously interact with the audience as part of the performance. This is a subtle but powerful way of conveying messages directly to the audience (community members). Few techniques that will aid audience and performers' interaction are aside monologues, one-on-one interaction, and projection. A performer can also activate audience participation by inviting them to be part of a dance, singing, drumming, and sometimes actually performing with them.

\section{Creating community ownership of Participatory Theatre projects.}

Community ownership of developments project according to Homan (1999) is an important aspect of the community development process. The initiation stage of the development process to its execution stage must always have the active involvement of key community members. There are various ways of creating viable community ownership of participatory development projects. The community's involvement in all the project stages right from the execution process to the end or completion of the project. The community should not only be involved in the identification and selection of the problem alone but should be involved in all the phases of the project as this will help them determine the next step after the facilitator has left the community.

\section{The community involvement in the problem identification process}

Mda (1993) postulates that the way to make a community own a participatory project is through the involvement of the community in the problem identification process or stage. When the community itself identifies their problems they are highly committed to finding remedies to them. Dreier (2007) also stated that "if the issues present in the community are accurately identified in a collective and participatory manner, then there is added potential for social and behavior change". When the community is engaged actively and not passively they feel a sense of ownership and are highly committed to meeting the goals of the project. Mda (1993) further argued that the community must actively be involved in selecting an issue and projects that are of ultimate importance to them. A project should not be imposed on the community at any point in time; consultation is a non-negotiable element in this regard. This gives them a sense of ownership and not a project or an imposed on them or the community. The facilitator should only serve as a guide to give direction and expertise in achieving his aims and objectives as well as that of the community. The project must serve as a voice for the voiceless. The facilitator must make sure that the issue tackled in the project represents the view of the masses in the community. When community members easily identify themselves with issues being discussed, they can contribute to the discussion thereof. This helps re-enforces the initiatives of the community and strengthens the trust between the community members and facilitators. Local community residents should be encouraged to partake in development that preserves and promotes their culture. Theatre is one of the surest ways through which a community can preserve its culture. Theatre should therefore not be left out in the development plan of a community.

\section{Conclusion}




\section{Macrothink

Communities have different needs. These needs may be felt by individuals or the entire community. Development practitioners must strive to involve community members in the assessment of such community needs. Involving community members may lead to the discovery of what is truly needed; whose provision will lead to real development. Participatory theatre practice has been identified as a community-based approach that provides a viable platform for such engagements. If fully and properly utilized, the participants will gain a deeper understanding of their community and gain a proper purview of their development dynamics and how to accurately address them. Local ownership, which is key to every community development practice is one advantage participatory theatre wields. It harnesses the creativity of both facilitators (outsiders) and community members in the promotion of indigenous development solutions. If communities are involved and assisted to plan and manage their development issues, the outcome is more likely to be accepted by all as well as meeting their real needs.

\section{References}

Adebo, S. (2000). Training Manual: Participatory Rural Appraisal. Addis Ababa: Freelance Consult.

Asante, E. (2016). Engaging Communities for Development Action; The Theatre for Development (TfD) Approach. International Journal of Research in Humanities and Social Studies, 3(9), 1-10.

Asante, E., \& Yirenkyi, S. M. (2020) Rural tourism in Ghana: potentials and prospects of asebu traditional area. International Journal of Innovative Research and Advanced Studies (IJIRAS), 7(5).

Asiama, E. K. (2016). The use of story-telling for theatre education. Accra: University of Ghana press.

Brennan, M. A., Kumaran, M., Cantrell, R. \& Spranger, M. (2014). Empowering your community: Stage 3, goal setting and strategy development. Gainesville: University of Florida Institute of Food and Agricultural Sciences. Retrieved from

http://edis.ifas.ufl.edu/fy764

Chambers, R. (1998). Whose reality counts? The quiet revolution of participation and numbers. Working Paper 296. Institute of Development Studies, Brighton, UK. Retrieved from http://www.ids.ac.uk/files/Wp296.pdf

Chambers, R. (2014). Rural development: Putting the last first. London: Routledge. https://doi.org/10.4324/9781315835815

Dreier, P. (2007). Community Organizing for What? Progressive Politics and Movement in America. Marion Orr, editor, University of Kansas Press, USA.

Dunham, A. (1970). Community development - whither bound?' Community Development Journal, 5(2), 85-93. https://doi.org/10.1093/cdj/5.2.85

Homan, M. S. (1999) Promoting Community Change: Making it Happen in the Real World 
(2nd ed.). Brooks/Cole Publishing.

Kerr, D. (1995). African popular theatre. London: David Philip Publishers.

Malamah-Thomas, D. H. (1986) Innovative community theatre for integrated rural development (C.T.H.I.R.D.) in Sierra Leone: the Twlu workshop experience. International Review of Education, 33(2), 229-258. https://doi.org/10.1007/BF00598484

Manteaw, B. (2008). From tokenism to social justice: Rethinking the bottom line for sustainable community development. Community Development Journal, 43(4), 428-443. https://doi.org/10.1093/cdj/bsm015

Ordrink, S. R. (1996). Participatory approach to national development planning. Asian Development Bank Report. Retrieved July 17, 2017, from iteresources.worldbank.org/INTEASTASIAPACIFIC/Resources/.../Brief_ADB.pdf

Pigg, K. (2010). Community informatics and community development" in Community Development. Journal of the Community Development Society: Special Issue on Community Informatics and Community Development. pp. 36-47.

https://doi.org/10.1080/15575330509489867

Prentki, T. (1998). Must the show go on? The case for Theatre for Development. Development in Practice, 1(1), 419-429. https://doi.org/10.1080/09614529853440

Richards, G. (ed.) (2001) Cultural Attractions and European Tourism. CABI Publishing, Wallingford, UK. https://doi.org/10.1079/9780851994406.0000

Salhi, K. (1998). African theatre for development: Art for self-determination. London: Intellect Books.

Suguna, B. (2006). Empowerment of Rural Women through self-help groups. Discovery Publishing House.

\section{Copyright Disclaimer}

Copyright for this article is retained by the author(s), with first publication rights granted to the journal.

This is an open-access article distributed under the terms and conditions of the Creative Commons Attribution license (http://creativecommons.org/licenses/by/4.0/). 